\title{
Managing maritime automobile terminals: an approach toward decision-support model for higher productivity
}

\author{
Bojan Beškovnik and Elen Twrdy
}

University of Ljubljana, Faculty of Maritime Studies and Transportation, Portorož, Slovenia

\begin{abstract}
The article describes actions and strategies to obtain higher productivity on maritime automobile terminals. The main focus is on elaboration of efficient and effective organizational structure to model and implement short-term, mid-term and long-term strategies. In addition, with an empiric approach we combined the analyses of current findings in important scientific papers and our acknowledgments in practical research of north Adriatic maritime automobile terminals. The main goal is to propose actions towards increasing system's productivity. Based on our research of the north Adriatic maritime automobile terminals and with Lambert's model an in-deep analysis of limiting factors, user's expectations and possibilities for productivity increase has been performed. Moreover, with our acknowledgments a three-level decision-support model is presented. With an adequate model implementation it is possible to efficiently develop and implement different strategies of productivity measurement and productivity increase, especially in the fields of internal transport productivity, entrancelexit truck gates operations and wagon manipulations. According to our observation a significant increase might be achieved in all three fields.
\end{abstract}

KEY WORDS: Supply chain; Maritime automobile terminals; Automotive industry; Finished vehicle logistics; Productivity measuring; Decision support model; Management.

\section{INTRODUCTION}

A maritime automobile terminal can be defined as a system with an important role in the management and coordination of finished vehicles flows. It is becoming the basic multimodal node in the automotive logistics network, because it provides an important link between maritime and inland transport and in most cases its role is significant serving also as a buffer system.

From the logistics perspective, a maritime automobile terminal also provides logistics operations therefore it should be assumed that these multimodal nodes perform added value operations (Marlow and Casaca, 2003). According to Mendonça and Dias (2007) terminals can provide economies of scope if they can allow services generally related to pre-delivery inspections (PDI), postponement customization or dissembling vehicle services.

It is evident that the entire automobile industry builds new logistics concepts of finished vehicles distribution on agile automobile terminals. Consequently, issues related to productivity are becoming more important than ever.

Corresponding author: Bojan Beškovnik

e-mail: bojan.beskovnik@intereuropa.si
Different analyses and agent-based tools have been proposed to optimize planning processes (Mattfeld and Kopfer, 2003; Davidsson et al. 2005; Fischer and Gehring, 2005; Aras, Aksen and Tekin, 2011), with an aim to reduce the costs per unit handled through the terminal, minimize ship in-port time and secure higher efficiency of the entire chain. Davidsson (1996) define agent-based tool as a system capable of interacting independently and effectively within its environment in order to accomplish given or selfgenerating tasks.

Carbone and De Martino (2003) expose the role of creating synergies and converging interests between all players in an automotive transport chain of finished vehicles, in order to guarantee reliability and high productivity levels. Dias, Calado and Mendonça (2010) and Gierlach and Torresani (2008) also expose the importance of maritime automobile terminals performance. Namely, productivity of the system can be classified as the source of competitive advantage in the corresponding automotive network. It is of crucial importance that the management of a maritime automobile terminal analyse a vast number of components to find an optimal working process, to harmonize all the relevant costs and develop opportunities for productivity increase. According to Mattfeld and Kopfer (2003) shortterm reaction characterises operational decisions rather than planning processes. 
Thus, the issue to implement a decision-support model for operational efficiency on a maritime automobile terminal is becoming an important challenge for the management of a maritime automobile terminal as they are forced to constantly re-develop mechanisms to measure productivity and increase it primarily without high financial investments. With an appropriate organizational structure the problem of planning and placing adequate operational strategies can be solved efficiently.

This is of special importance for maritime automobile terminals in northern part of the Adriatic Sea, because terminals in Koper and Monfalcone suffered from strong congestion in 2007 and 2008. Namely, deep-sea vessels were not berthed due to the overcapacity of the terminal and difficulties to organize regular dispatch of trains and trucks from the port. Moreover, compound strategy for different manufacturers was creating internal operational problems, as enormous internal vehicle movements were needed to satisfy client's orders. To some extent that scenario is directly connected to missed middle-term and long-term planning strategy and inappropriate short-term operational reactions. Based on the increasing trend of new vehicles in arrival and departure through northern Adriatic maritime automobile terminals in 2010 and 2011, and new production plants in central Europe, which are looking to use north Adriatic Sea ports as exit ports for inbound flows, it is expected that such scenario might be repeated once again in the near future. Consequently, there is a strong need to analyse existing planning strategy in these systems and to empirically develop a decision-support model for operational efficiency. It has been realised that simulation tools and techniques in use do not contribute enough strategic decisions. In addition, there is no hierarchic level decision in use, thus a lack of long-term and short-term decisions are present Our research of productivity measuring and planning and model proposal might be used as a platform for internal reorganization and new strategy definition, especially in the port of Koper.

\section{THE BASIS FOR DECISION-SUPPORT MODEL}

\section{Research cases: Port of Koper and Port of Monfalcone}

Different elements influencing automobile terminal productivity have been analysed on the cases of Koper port and Monfalcone port. Due to the different size of systems, we analyse different operational and decision-making situations which appear in small maritime automobile terminals as well as in the big ones. Moreover, both ports are situated in the northern part of the Adriatic Sea and are competing almost for the same market in import and export. The automobile terminal in Monfalcone operates on 93000 square meters of yard, with a capacity to hold approx. 4300 vehicles at once. Vessel discharging capacity is approx. 1200 vehicles per day and the terminal can accommodate deep-sea vessels. In 2010 the terminal handled 64607 vehicles, with an increase of 23 per cent over 2009 volume. This is still far from the record throughput realised in 2008, when the terminal handled 122
000 vehicles. The Monfalcone automobile terminal handles Renault, Fiat, Opel, Dacia and Merceds vehicles and offers washing, de-waxing and installation services and pre-delivery inspection (PDI).

On the other hand, Koper port is one of the biggest European automobile ports. It has been ranked on 16th place in 2010, with the annual volume of 379250 vehicles. Export volumes are a little bit higher, with 200253 vehicles, compared to import volume of 178997 vehicles. The record throughput was achieved in 2008, when 568941 vehicles were handled. The terminal has 750000 square metres of open spaces and 125000 square metres of covered place in a five floor garage. The static capacity is approx. 50000 vehicles, with 6000 positions in the garage. The terminal can handle till 600000 vehicles per year therefore the actual utilization is approx. 65 to 70 per cent. The main clients are Chevrolet, VW, Opel, KIA, Hyundai, etc.

According to increasing trend of the annual throughput it is foreseen that both terminals might suffer operational problems in the coming period, especially due to new production plants in development by Mercedes-Benz in Hungary, FIAT in Serbia and increasing production by KIA in Slovakia, Hyundai in Czech Republic and by Suzuki in Hungary.

\section{Theoretical base for efficient model development}

An efficient terminal has to perform a quick transhipment of vehicles to and from ships and a dispatch of vehicles by train or truck from the system. The complexity of processes on the terminal provides many opportunities for improvement (Böse, Piotrowski and Windt, 2005; Fischer, 2004). In addition, traditional handling process is still in use on automobile terminals where vehicles have to be transported from the ship to the terminal area by drivers. Consequently, special attention must be given also to labour force as automobile terminals still significantly depend on it (Fischer and Gehring, 2005). Of course, other traditional elements have to be considered, too - like handling systems, the automation level, EDI between different parties, the shape of yard area, etc.

The productivity on a maritime automobile terminal has to be analysed also through different accompanying services. These services are generally related to damage inspections, waxing and de-waxing, polishing, pre-delivery inspections, repairs, vehicle customization and completion, etc(Holweg and Frits, 2001). Moreover, a maritime automobile terminal took a special role in supply chain during last decades with different services in dissembling of imported vehicles to export "semi-knocked down - SKD" vehicles to special export markets in order to avoid higher taxes (Carbone and De Martino, 2003). At the same time a maritime automobile terminal might be used as a logistics platform for reassembling of SKD vehicles. A common reason for opening a dissembling vehicle services is the avoidance of high customs-related expenses for the import of finished vehicles imposed by economically vulnerable countries (Klug, 2010).

As a vast number of different elements influence organizational structure, processes, productivity and 
economic results it is important to categorise them in different groups. The Lambert's model (Lambert, 2001) is a helpful tool to define elements and analyse systems exposure on internal and external limiting factors. Based on this model an in-deep analysis of limiting factors, user's expectations and possibilities for productivity increase can be analysed and defined. Thus the model deals with:

- The elements influenced by the structure of automotive supply chain for finished vehicles,

- The management components for better integration of the complete automotive supply chain,

- The business processes and technical characteristics.

In addition, acknowledgments obtained with this model present the basis to build a decision-support model for a maritime automobile terminal and to find possibilities for performance increase. Moreover, it is a good base to determine actions toward efficient productivity measuring and increasing efficiency.

\section{DEFINING ELEMENTS INFLUENCING AUTOMOBILE TERMINAL PRODUCTIVITY}

\section{The supply chain structure and expectations}

A maritime automobile terminal is one of the partners in the supply chain of finished vehicles, with the special role as it has to provide infrastructural elements and effective processes for multimodal services. Consequently, the terminal has to work simultaneously in several directions. On the one hand the management of an automobile terminal has to build a good commercial partnership with traditional clients as shipping lines, logistics operators, inspection houses, truck hauliers, rail operators etc, and on the other hand with car producers, their sellers and dealers.

All these users of the system's services have different expectations. Their business depends on the efficiency of a terminal and that is why the management of a maritime automobile terminal has to act as an active speaker to all parties in order to consider their priorities and needs. Surely, the most important subjects are car manufacturers or their representative companies, because they control flows of vehicles, they choose transport routes and decide about additional services. They look for the possibility to have higher stock on the terminal with long free time rather than use their limiting storage capacities at producing places. At the same time deep-sea carriers and local RO-RO ship owners are a group of important business partners (Mendonça and Dias, 2007) and their expectations are directly connected, mainly with the service of the berth subsystem. They look mostly for short berthing time, even this might cause congestion in the supply chain at the land side. On the contrary, truck hauliers and rail operators look for shorter waiting time when delivering vehicles to the terminal.

Understanding all expectations and needs helps the management of a maritime automobile terminal to balance different impacts. Namely, a very strong conflict appears from the opposite interests of the deep-sea carriers and terminal management. Carriers are in pursue of shorter stop time for their vessels, even this requests higher number of drivers and increases costs to the terminal management. Namely, the terminal management is primarily looking for lower costs, although this might reflects in higher berthing time for the carriers. The terminal aims to do higher throughput, but with lesser number of drivers or manipulation machinery.

Besides carriers and car manufacturers' expectations, other needs and expectations have to be treated with special care, too. Shipping agents, inspection hoses, forwarders, trucking hauliers etc. also have their expectations. Although locally present subjects have essentially less influence on the operator's business decisions they are among the crucial subjects in communication with the car manufacturing companies or carriers. They frequently complain about the lack of communication, number and gravity of damages on the vehicles, new safety procedures and terminal tariffs.

Consequently clear delimitation of competences in decisions and communication with external subject has to be introduced in terminal management. According to our observation this is not the practice in case terminals. Namely, the communication process with a vast number of clients and on a daily basis is not performed by the management level meanwhile management level makes pressure on lower labour force and manipulation machinery in use. There is a lack of following processes: customer relationship management, demand management, customer service management, customer order fulfilment and productivity management. Actual situation calls for modifications and better co-ordination processes implementation.

\section{Integration in complete automotive supply chain and reduction of limiting factors}

It is very important for the terminal management to define different internal and external factors arising from integration of complete automotive supply chain, and which are influencing productivity of the system. Internal factors are most often under control of the terminal operator and the management of the terminal, therefore the management has to be focused on their reduction. With our observation we have acknowledged that beside the elements of terminal layout and configuration, labour productivity and infrastructure in use, other elements as capital resources already invested, accumulated debts, development strategies, ownership structure are also internal factors, with strong impact on the everyday activities. However, the management of the terminal in Koper and Monfalcone has an influence on these limiting factors but very often, certain decisions are not under their control, like expanding the layout over actual borders, additional extensive investments in infrastructure, etc. To the some extent, expansion is possible at the terminal in Koper, because there are not strictly predefined borders between other port terminals. Thus, enlargement is possible, but consensus with other systems is required. 


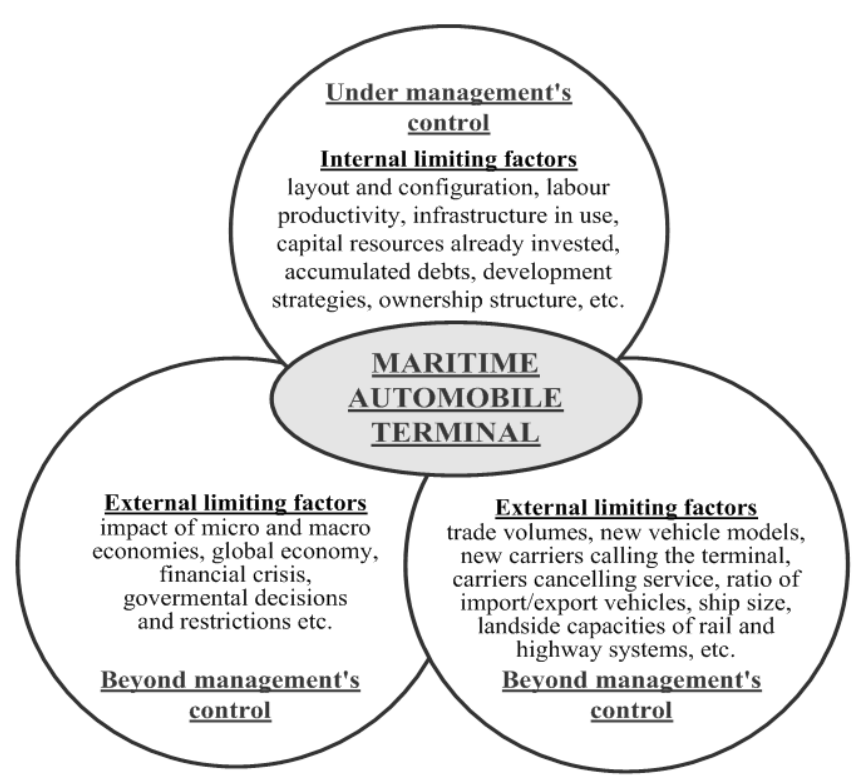

Source: Prepared by authors

Fig. 1 Limiting factors influencing maritime automobile terminals.

Unfortunately, there are also external factors which are beyond the control of terminal's (Bergantino and Musso, 2011). Based on our research we have realised that this group consists of two main segments. The first one is in direct relation with commercial activities of different subjects in the entire automotive logistics of finished vehicles and the second one in the impact of micro and macro economies which influence the automotive industry. Namely, trade volumes, new vehicle models, new carriers calling the terminal or carriers cancelling their calls, the ratio of import or export vehicles, ship size and arrivals, landside capacities of rail and highway systems are just one of the external elements with strong impact on the productivity of a maritime automobile terminal. The impact of global economy has huge consequences on the automotive industry. This has been evident during last three years, when well developed automotive industry suffered from financial crisis and annual throughput in observed case terminals decreased significantly. Both maritime terminals perceived these changes, through decreasing of vessels calls at terminal and decreasing/increasing number of road hauliers going out of the market due to irresistible financial problems. The management of the terminal has to focus its actions primarily on measures that are under its control. Of course, a close follow up has to be performed also on reduction of external limiting factors, because they have impacts on internal limiting factors with a delay.

\section{Business processes and technical characteristics}

The third element which has an impact on the productivity and attractiveness is connected with internal business processes and technical characteristics of the terminal. Namely, a variety of types of maritime automobile terminals are in function around the world differing in layout, shape, process organization, handling technology and automation level, static capacity for storage, etc. Terminals also differ between regions, countries and very often within certain countries (Hall, 2004). According to our analysis this is also the situation in the northern Adriatic. Although maritime automobile terminals in Koper, Monfalcone and Venice are completely different, even they compete for the same market and same clients.

A typical maritime automobile terminal consists of three subsystems: berth, yard zone for vehicle storage and delivery zone for vehicle handling on trucks or rail wagons. All three subsystems are important factors in obtaining higher productivity. Their technical characteristics influence internal working processes, manpower and the level of automation in the entire process. Thus, a vast number of components have to be analysed to find opportunities for productivity increase (Dias, Calado and Mendonça, 2008). Following elements should be analysed to find an optimal working process and harmonize all the relevant costs:

- Different berths in use, their location and availability,

- Different length of driving lanes for vehicles,

- First point of rest zones,

- Loading/discharging tracks, capable of accommodating an entire train, which differ in length and position on the terminal,

- Vehicle storage areas, with different shapes, technology and static capacity,

- Possible closed garage and its location,

- Check in/out gates or entry points,

- Workshops for PDI service and waxing, etc.

The layout of a certain maritime automobile terminal has very strong impacts on the infrastructure and on commercial activities as well. Moreover, the infrastructure of different subsystems is adapted to the layout which determines the position of subsystems, connections among them, technology in use, etc. The layout of a terminal is therefore of crucial importance to model proper logistics processes and organize everyday operations. It has been established that it depends on different elements:

- Space availability and possibilities for further expansion on inland side and on sea side,

- Regional and local inland transport network in use or possibilities for constructions,

- Number of maritime automobile terminals and inland automobile terminals in surroundings,

- Technology in use for manipulations,

- Interests of deep sea or short sea carriers to call the port or terminal,

- Daily turnaround of vehicles in arrival and departure and commercial interests for stock buffer on a maritime automobile terminal, etc.

Defined elements have been analysed primarily on the terminal at Koper, because in Monfalcone, there is a macro issue related to the actual capacity in all three subsystems. 
Improvements in described elements cannot contribute significantly in systems improvement. Just the opposite is the situation in Koper port. Namely, the automotive terminal uses different berths for deep-sea and smaller RO-RO vessels accommodation. Moreover, different storage zones are in use in the port area, where they lay just on the opposite side of the port. The same situation is in delivery zone, because the terminal uses 6 rail ramps, which are situated in different port areas. This requires special set-up for first point of rest zones and utilization of yard zone for vehicle storage.

\section{ACTIONS TOWARD EFFICIENT MEASURING AND INCREASING PRODUCTIVITY}

\section{Measuring productivity}

Different problems and real time decisions influence processes of measuring and actions to increase the productivity. Consequently, the management of a maritime automobile terminal has to analyse a vast number of different parameters, which change continuously (Böse and Windt, 2007). Thus, it is very important to check and adjust them frequently. According to Mattfeld and Kopfer (2003) operations at the automobile terminal are mostly characterised by short-term reaction, rather than planning. Such daily operational decisions are the result of high volumes of vehicles to be discharged in a very short period and complexity of services. Consequently, it becomes very difficult to measure the productivity of manpower, the utilisation of suprastructure and to plan the next operational activities. Moreover, with such processes it is difficult to increase productivity on all three subsystems, as the confusion and short-term decisions influence the entire internal logistics chain. Usually this calls for additional manpower per shift or extra capacity to cover peak situation (Mattfeld and Kopfer, 2003).

This confusing situation has been ascertained in both case terminals. Although operational level recognises of vital importance the constant productivity measuring for detecting opportunities in system's development and optimization, this is not the practice in use. During our observation of both systems it has been established that productivity is directly related to the transfer functions of vehicles inside the terminal area. The management actually controls and manages following measures: the number and movement rate of vehicles on the berth per hour or shift, the use of internal shunting road vehicles per hour or shift, yard occupancy per day, number of employed drivers for internal vehicle shunting per shift, workers employed in gate operations or at workshops.

The terminal does not follow other measures as number of trucks at the entrance in the terminal, number of wagons waiting at the shunting station, average waiting time of truck to be served, average waiting time per wagon to be discharged or loaded, average time to unload a block train and average transported distance in internal shunting. For sure the terminal performance depends significantly on the capacity and efficiency of terminal gates, efficiency in utilization of rail tracks and discharging ramps for wagons and internal road network. These elements determine the performance level of the entire system as well.

It has been also realised that the waterside operation on berths as predefined as highly significant determinant of productivity is adequately measured. The reason is in strong pressure from deep-sea carriers. This has huge effects on other processes, because the process of serving a berthed vessel has a priority. Consequently the process of productivity measuring at observed terminals is undoubtedly a complex process, because different elements are in interacting relations. If only one factor especially related to the berth process changes all other elements perceive it directly either in negative or positive way.

Moreover, we realised that there is a difference in productivity comparison between observed systems. It is important to distinguish between net and gross productivity. Namely, net and gross productivity vary between systems. There is no guarantee that systems achieve the same net productivity under the same gross productivity achieved. The direct comparison is therefore inapplicable, because net time is the elapsed time minus time unable to perform operations (like weather conditions, congestions, shift breaks, etc.), which differ between systems.

\section{Increasing productivity}

Every system is looking how to increase productivity, which has direct impacts also on financial results. For sure the terminal must avoid additional shunting processes inside the terminal area. According to our observation automobile terminals very frequently prepare vehicles planned for loading in advance. They position requested vehicles close to the berths or in delivery zones also one or two days in advance. Small terminals like the one in Monfalcone are limited with space for such operations. Anyhow the terminal is forced to perform these processes in order to make enough free space for new incoming vehicles. Namely, based on obtained commercial data vessels on the same voyage very often bring some quantity of vehicles for European market and load European production for non-European markets.

Although the space is not the problematic issue for Koper the same procedure is in use, especially when two or more car vessels are expected on the same day or when the terminal receive a preannounce for big outgoing quantity of vehicles for the same day. Such operational procedures reallocate the manpower and shorten the stops at terminal, but at the same time rise additional manipulations and additional costs. Improvements can be done to define optimal areas for this service, which should be closer to the berth. These positions should be dedicated for this kind of service. With our observation we found two positions, which are actually used by the container terminal. Anyhow a consensus might be achieved with an internal agreement between terminals.

From the revenue perspective the automobile terminal makes a good profit when vehicles stay on the terminal for a longer period. This has important positive impacts on 
revenue, but negative results in operative processes. Namely, congestion on the yard influences all subsystems. According to our findings a delivery zone is very often used to accommodate vehicles, which remain in the system for a longer period. The influence on the productivity is very high, therefore the management looks for measures which gain higher revenues or reduce number of vehicles in the system. The solution is in progressive storage tariffs, which can even double after some period. Usually a free storage period is in use and after that period the commercial tariff is in use. For storage time over passing 30 or 45 days a progressive tariff should be used.

Such solutions of optimization in a maritime automobile terminal can be carried out without high investments. It has been established that some other solutions are easily realizable, such as reducing transport routes, reducing the distance between berth and first point of rest, extended operational hours at terminal gates, etc. These possibilities must be considered as priority, although the use of new technologies and investment in infrastructure has definitely greater impact on productivity. The management must decide which measures it is better to perform first in order to achieve maximum handling and transport productivity and reduce costs and maximize the profit at the same time. The analysis shows that observed automobile terminals in Monfalcone and Koper have possibilities to apply them, before they invest in infrastructure or in terminal modernisation.

\section{MODEL PROPOSAL TO IMPROVE PRODUCTIVITY}

\section{Three-level decision-support model}

Based on the analyses performed with Lambert's model on northern Adriatic automobile terminals it can be ascertained that it is necessary for the management of the terminal to set up its own model how to follow internal and external limiting factors, to measure and improve productivity as they have unique requests by the carriers and car manufacturers. It has been realised that specialists in the planning service are the key generators of productivity increase, because they are involved in daily decisions and consequently they have real time information for best solutions. In addition, the lack of decisionsupport processes has been established. Consequently, we worked out a three-level decision support model for the management of a maritime automobile terminal with three basic levels: management level, strategic level and operational level. In this way every level could take an active position in decision processes.

According to the model the management level has to deal with long-term decisions regarding infrastructure, technical maintenance, terminal layout, suprastructure modernisation on all subsystems, etc. Commercial activities with deep-sea carriers, RO-RO operators and car manufacturers should be also managed from the management level. The main reason for such delimitation is in hierarchy of decision taking, as the planning service usually does not have the power to influence such decisions.
In most cases their proposals are evaluated to some extent but without any guarantee to be applied as such.

The second and third level of proposed model are the central part of knowledge, experience and short and mid-term decisions. It is important that information flow between these two levels is efficient in order to set up the strategy of improving the performance of the system's bottlenecks. Namely, the second so-called strategic level involves the mid-term and short-term actions regarding the use of available ground space, increases or decreases the number of working hours and shifts, the utilisation of internal or external manpower, outsourcing operations and services, etc. On the bottom is the third so-called operational level. The operational level deals with daily and real-time operational decisions, which have direct impacts on productivity and efficiency.

According to a vast number of different decisions, to follow high quality standards of automotive logistics and to link, inform and guide all three decision levels as per proposed model we foresee the necessity of appointing a quality and productivity manager on automobile terminal at Koper port. Namely, top management deals with described fields, but due to the time limitation and task prioritisation the field is not covered properly. The person appointed should manage and control productivity of the entire system and coordinate the activities with specialists from all presented levels as well as propose long-term development strategies. The lack of such organizational structure and actions has been ascertained in observed systems.

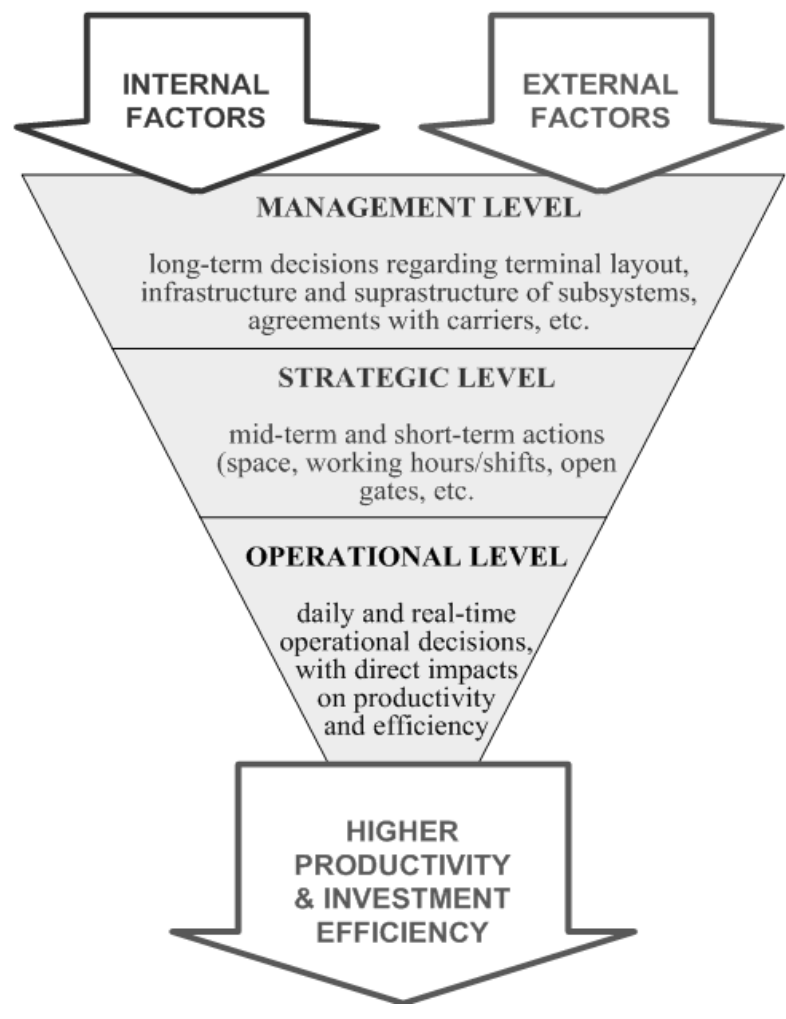

Source: Prepared by authors

Fig. 2 Three-level decision-support model. 


\section{Strategies and short-term decisions}

It is very important for strategic and operational levels to know system's buffer limits and have wider data of planned inbound or outbound flows through the terminal. Gierlach and Torresani (2008) expose the problem of planning and placing adequate operational strategies, because although the logistics company receives information in advance relating to the total volumes and types of vehicles, exactly when and where delivery is required is generally not known in advance due to the throughput unreliability of the assembly plants. Therefore, exact truck or rail arrivals into the terminal area are almost impossible. This is the situation also in observed terminals. But, the terminal at Koper persist on 24 hours pre-advise and work order preparation. This way congestion is minimised and higher productivity can be achieved.

Close relationship and accurate data exchange between all parties are therefore necessary. According to Klug (2006) decentralised and modular networks that are cooperative-oriented, autonomous and indirectly coordinated should be developed. Consequently, automobile terminals will not be able to obtain higher effectiveness without effective and efficient coordination in the entire chain. This is the filed both analysed terminals have place for improvements. With decision-support model introduction it is possible to intensify communication with all partners in the supply chain. Consequently it becomes easier to obtain and analyse received and available data in advance, in order to place adequate mid-term and short-term strategies.

The research confirms that the management of a maritime automobile terminal in Koper and at Monfalcone follows the strategy of maximising berth occupancy. The terminal secures free berths immediately after a vessel's arrival in the port and as quickly as possible discharging and loading processes. Usually, the number of drivers is higher that needed, just to satisfy carrier's plans. Consequently, we did not find possibilities for higher productivity on the berth subsystem, although a cost reduction measure might be applied through efficient planning of drivers.

On the other hand, based on our observation in the case terminals it has been established that a strategy in reducing the distance between berth, the first point of rest or storage area could decrease the vessel's dwell-time and internal productivity significantly. Over $20 \%$ improvement can be achieved with modification, which should be realised also through agreements with other terminals, especially container terminal. Such agreements and decisions do not require financial investments, but just modification in internal working processes and procedures.

We found out that issues of gate entrance optimization are also important elements. Actual gate are not designed in such a manner as to provide the required number of lanes needed at peak hours of traffic volume for both directions. Consequently regular measuring of gate utilisation and waiting time for trucks should be provided. Namely, during the observation it has been acknowledged that one lane is very often closed even the average waiting time is over 30 min. Moreover, truck drivers must obtain a permit to enter the port area at truck terminal, which is 15 min. away from the main entrance. Consequently, with administrative process additional $30 \mathrm{~min}$ are lost. Thus, operational strategy should be focused on the exact balance to obtain optimal gate throughput. With a short-term decision when to open an additional gate and with office transfer closer to the gates, it could be possible to increase productivity at the gates for 10 to $15 \%$. Additional improvement might be done with the use of new identification and information technologies. But, an adequate investment must be planned by strategic and management level and finally confirmed by the owners.

The third field of improvement includes operational actions and decision related to loading and discharging vehicles from the wagons. Actual IT programme in use does not support real-time decisions, because there is no information about arrival of a block train on the internal rail tracks equipped with discharging ramps. Thus it is impossible to organize working process properly. It happens that drivers are waiting for the composition or that wagons are waiting on rail tracks for entire shift. It is anticipated that with upgraded IT solution and new documentation process it could be achieved a $15 \%$ increase in terminal's productivity.

Based on findings and through the adoption of proposed decision-support model we see potentials for higher productivity in the following fields:

- $20 \%$ increase in internal transport productivity.

- $10-15 \%$ increase in efficiency of entrance/exit truck gates.

- $15 \%$ increase of productivity on wagon manipulations.

\section{Long-term decisions influencing manpower productivity}

Surely, labour force is of great importance on maritime automobile terminals, because loading and discharging operations and internal shunting are performed by drivers. This is the practice also in Koper and Monfalcone, where constantly look to have trained and satisfied employees. On the other hand, the terminals face big problems of labour force as trades unions are becoming very strong, even on that level to obstruct the prescribed norms of operational efficiency. This problem has been especially ascertained in the observed maritime automobile terminal at Koper.

Mid-term and especially long-term strategies taken by the management level should include issues related to work and safety rules, workforce motivation, training procedures and adequate working timetables, because these elements directly influence gross labour productivity. It has been confirmed that where automobile terminals operate under more restrictive regulatory and difficult labour conditions this has direct impacts on manpower productivity and finally on system's throughput and efficiency.

The pressure of increasing productivity by carriers and land transport operators force the management to increase the number of hours and shifts when terminal gates are open. Namely, gate hours are often a limiting factor, because vessels can be unloaded 24 hour a day or 7 days a week, yet 
the flow of vehicles through the terminal stops in the yard area if the gates are not operative. This is the practice at Koper terminal, where working hours at the truck gates are limited till $22 \mathrm{hrs}$. Almost the same situation is valid for rail transport, as the system does not handle vehicles on Sundays. But there are negotiations to extend working hours for rail transport also on Sundays. Consequently, the pressure on manpower increases due to extended working timetable and crushed working hours. Thus, it is up to the management to balance the pressure on labour force and maximise the system's utilization.

According to our findings, both systems achieve high standards in manpower productivity. The reason is in flexible employment. Namely, most of the drivers at Koper terminal are just contractually employed, through private companies. Just a small part of drivers has regular employment in the port.

Obtaining higher manpower productivity is therefore mostly connected to the optimal short-term operational strategy chosen by the operational level. For sure, the management must be careful in working hour extension, as this might result in manpower resistance and decreasing productivity.

\section{CONCLUSIONS}

The pressure of increasing productivity on maritime automobile terminals becomes a key strategy of the entire automotive industry. Nowadays, a maritime automobile terminal must perform a range of different logistics and valueadded services under cost efficiency and time saving. Thus, it has been realised that a vast number of different impacts influence internal processes, productivity and economic results. Moreover, it is becoming of crucial importance to analyse all limiting factors, user's expectations and possibilities for productivity increase with a modular approach.

With our research of productivity measures in the north Adriatic maritime automobile terminals the conclusion is that a decision-support model appears to be an adequate systematic approach to take necessary long-term, mid-term and short-term decisions. Our proposed three-level decisionsupport model consists of three-level decision related groups in a maritime automobile terminal. Described organizational structure and related activities were not detected in analysed systems, but in case implemented would increase decisionsupport processes and long-term development.

With an adequate model implementation it is possible to develop different strategies of productivity measurement and improvement. Namely, three main fields of productivity increase were identified, which are not measured by the management. These fields are: internal transport productivity entrance/exit truck gates and wagon manipulations. According to our observation a significant increase might be achieved in all three fields.

Consequently, every decision level has to work out different strategies of commercial and operational activities, which should be combined and internally adjusted. Moreover, the logic and working procedures should be used with agent- based tools, which can simplify every-day operational decisions, but cannot replace strategic decisions. This way analysed case systems might be prepared to accept additional volumes of finished vehicles. Thus, they would be prepared to support new production plants from the surroundings and prevent bad scenarios as they were experienced just a few years ago.

\section{REFERENCES}

Aras, N. Aksen, D. and Tekin, M.T., 2011. Selective multidepot vehicle routing problem with pricing. Transportation Research Part C. Emerging Technologies, 19(5), pp.866-884.

Bergantino, A.S. and Musso, E., 2011. The role of external factors versus managerial ability in determining sepaorts' relative efficiency: An imput-by-input analysis through a multi-step approach on a panel oh Southern European ports. Maritime Economics and Logistics, 13(2), pp. 121-141.

Böse, F. and Windt, K., 2007. Autonomously Controlled Storage Allocation on an Automobile Terminal. In: M. Hülsmann and K. Windt, eds. Understanding autonomous cooperation and control in logistics, Berlin: Springer- Verlag, pp.351-363.

Böse, F. Piotrowski, J. and Windt, K., 2005. Selbststeurung in der Automobil-Logistik. Industriemanagement, 20(4), pp.37-40.

Carbone, V. and De Martino, M., 2003. The changing role of ports in supply-chain management: an empirical analysis. Maritime Policy and Management, 30(4), pp.305-320.

Davidsson, P., 1996. Autonomous Agents and the Concept of Concepts. PhD. Thesis, Lund: Lund University, Sweden.

Davidsson, P. Henesey, L. Ramstedt, L. Törnquist, J. and Wernstedt, F., 2005. An Analysis of Agent-Based Approaches to Transport Logistics. Transportation Research Part C: Emerging Technologies, Vol. 13(4), pp. 255-271.

Dias, J.C.Q. Calado, J.M.F. and Mendonça, M.C., 2010. The role of European «ro-ro» port terminals in the automotive supply chain management. Journal of Transport Geography, 18(1), pp.116-124.

Fischer, T. Gehring, H., 2005. Planning of vehicle transhipment in a seaport automobile terminal using a multi-agent system. European Journal of Operational Research, 166, pp.726-740.

Hall, P.V., 2004. Mutual Specialisation, Seaports, and the Geography of Automobile Imports. The Tidjschrift voor economiche en sociale geografie, 95(2), pp.135-146.

Holweg, M. and Frits, K.P., 2001. Successful Build-to-Order Strategies Start with the customer. MIT, Sloan Management Review, 43(1), pp.74-83.

Klug, F., 2006. Synchronised Automotive Logistics: An Optimal Mix of Pull and Push Principles in Automotive Supply Networks, In: M. Bourlakis et al., eds. Logistics Research Network Conference Proceedings, Newcastle, pp.187-191. 
Lambert, D.M., 2001. The supply chain management and logistics controversy. In: A.M. Brewer, J.K. Button and D.A. Hensher, ed. Handbook of Logistics and Supply Chain management, Oxford: Pergamon, pp.99-125.

Marlow, P.B. and Casaca, A.C.P., 2003. Measuring lean ports performance. International Journal of Transport Management, 1(4), pp.189-202.
Mendonça, M.C. Dias, J.C.Q., 2007. Postponement in the logistical systems of new automobiles marketed in Portugal: the Brands and quality. Total Quality Management \& Business Excellence, 18(6), pp.691-696.

Mettfeld, D.C. and Kopfer, H., 2003. Terminal operations management in vehicle transhipment. Transportation Research, Part A, 37, pp.435-452. 